\title{
BODY DYSMORPHIC DISORDER: A COMPREHENSIVE REVIEW
}

\author{
Farheen Malik ${ }^{1} \oplus$, Jawad Ahmed ${ }^{1} \odot$, Sundus Nasim ${ }^{1} \odot$, \\ Aiman $\operatorname{Ali}^{1} \odot$, Ahmad Rehan $\operatorname{Khan}^{2}$ (1)
}

${ }^{1}$ Dow University of Health Sciences, Karachi, PAKISTAN

${ }^{2}$ Department of Psychiatry, University of North Dakota, Fargo, North Dakota, USA

\begin{abstract}
Body dysmorphic disorder is psychiatric morbidity that comes under the spectrum of obsessive-compulsive disorders. Individuals suffering from body dysmorphic disorder are incredibly concerned about their minor or so-called defects to such an extent that their lives may be affected drastically. As a result of continuously thinking about the asserted defect, the individuals end up suffering from major depression, anxiety, and self-harm. Diagnosis of body dysmorphic disorder is based on the Diagnostic and Statistical Manual of Mental Disorders, fifth edition criteria. The management of body dysmorphic disorder consists of psychotherapeutic and pharmacological interventions. Body dysmorphic disorder is a hidden disorder and is often under-reported. It has been linked to muscle dysmorphia, substance abuse, and major depressive disorder. The lack of studies in different countries and populations has made this a topic that requires substantial input from researchers. Keywords: Body dysmorphic disorder, obsessive-compulsive disorder, somatoform disorders
\end{abstract}

\section{INTRODUCTION}

Negative statements regarding appearance often posses the potential of having an detrimental impact on one's self-confidence. However, when these comments are self-made and focused on a non-existent defect, they constitute a disorder called body dysmorphic disorder (BDD) (1). BDD first appeared in the American Psychiatric Association's (APA) Diagnostic and Statistical Manual of Mental Disorders, third edition, under the name 'dysmorphophobia' in 1987 (1). Diagnostic and Statistical Manual of Mental Disorders, fourth edition, and International Classification of Diseases-10 (ICD-10) placed BDD under "somatoform disorders", while today, BDD is depicted in Diagnostic and Statistical Manual of Mental Disorders, fifth edition (DSM-5), under the obsessive-compulsive spectrum $(2,3)$.

According to APA, BDD is a mental disorder characterized by an individual's preoccupation with a slight or non-existent defect to such an extent that it causes significant distress and impairs their functionality (4).

The presence of BDD varies globally from $1 \%$ to $2 \%$ in different cohorts, and the incidence rate is higher among females (5). The foci of concern vary among the affected individuals. Distressing appearance traits can include weight, head hair, skin, nose, teeth, and height $(6,7)$. The patients suffering from body dysmorphophobia undergo a daily struggle to achieve the perfect body type. The increasing popularity of taking selfies, coupled with a lack of self-confidence, often drives them to undergo cosmetic modifications in order to achieve a flawless look. This was termed as "Snapchat dysmorphia" (8). Individuals with BDD demonstrate an excessive preoccupation with their defect to a degree where this affects their mental health. This leads them to be depressed and can often contribute to the development of suicidal predilections. Due to a similarity of presentation, BDD can be misdiagnosed as major depressive disorder (MDD) or obsessive-compulsive disorder (OCD) leading to wrong treatment strategies (9). This review aims to provide an overall picture of BDD, its symptoms, diagnostic criteria, its effect on daily life, and management.

\section{SYMPTOMS OF BODY DYSMORPHIC DISORDER}

There are four main symptoms of BDD, which manifest in different ways (4). The symptoms are as following: preoccupation with the perceived or concerned; repetitive behaviors such as checking their appearance on a reflective surface, application of various products to hide the defect, skin picking, obsessive dietary habits, and thoughts of getting cosmetic surgery to rectify the defect; delusional beliefs such that people are mocking their appearance based on the defect. Consequential symptoms such as low self-confidence, avoidance of public places due to a fear of being judged, anxiety, and depressive symptoms where suicidal thoughts may be seen as well (4).

\section{DIAGNOSTIC CRITERIA}

Body dysmorphic disorder remains an under-diagnosed and inadequately treated disorder, despite being a common mental illness $(10,11)$. The timely diagnosis of BDD is crucial for the proper management of the disorder. The ICD-10 lists BDD under the category of somatoform disorders (2). The diagnosis of BDD is commonly based on the DSM- 5 criteria. It is being used in classifying as well as a diagnostic tool. It is published by the APA and serves as the principal authority for the diagnosis of psychiatric disorders. 
The DSM-5 criteria classify BDD in the chapter of "Obsessive-Compulsive and Related Disorders," along with OCD and several other disorders (12). The DSM-5 diagnostic criterion for BDD is summarized in Table 1 (13).

Body Dysmorphic Disorder Questionnaire and Body Image Disturbance Questionnaires are used for identifying BDD. They consist of a series of questions that assess an individual's perception and concerns about their physical appearance and the negative impact of those concerns on a person's life (14-16). BDD is diagnosed by mental health professionals/psychiatrists through structured interviews based on Structured Clinical Interview for DSM-5, BDD Diagnostic Module, or Body Dysmorphic Disorder Examination (BDDE). The severity of BDD can be assessed using scales such as the Yale-Brown Obsessive-Compulsive Scale Modified for Body Dysmorphic Disorder, the Psychiatric Status Rating Scale for Body Dysmorphic Disorder or BDDE. Scales called the Brown Assessment of Beliefs Scale and Overvalued Ideas Scale can be used by psychiatrists to gain further insight into BDD (14-16).

Body dysmorphic disorder can be misdiagnosed as OCD, social anxiety disorder, trichotillomania (hair-pulling disorder), MDD, excoriation (skin-picking disorder), eating disorder, or generalized anxiety disorder (16). Such misdiagnosis can hamper adequate treatment.

\section{GLOBAL PICTURE OF BODY DYSMORPHIC DISORDER}

Table 2 aims to provide a picture of some studies around the globe with varying populations. Researches are carried out globally trying to find out prevalence of BDD in different groups. A systematic review published in 2016 provided a comprehensive analysis of BDD among various study populations (17). It was found that the weighted prevalence of BDD in the adult population was $1.9 \%$, followed closely by adolescents with $2.2 \%$, where the student population reported a higher prevalence with $3.3 \%$ (17). The weighted prevalence was found most elevated among the population undergoing rhinoplasty (20.1\%) and general cosmetic surgery $(13.2 \%)$ (17).

\section{EFFECTS OF BODY DYSMORPHIC DISORDER ON LIFE}

Living with BDD means living with a distorted image of one's own body, low self-esteem, and thus having difficulty in accepting the way they look. The detrimental impacts of BDD stated down below make it evident that early diagnosis and treatment of this disorder are necessary to prevent future complications and consequences. Further long-term prospective studies are needed to study these side effects more profoundly. Figure 1 provides an overview of the detrimental effects of BDD.

\section{Body dysmorphic disorder influences students' life}

Body dysmorphic disorder might affect multiple aspects of an individual's life, including sleep, appetite, academics, occupation, and/or social life. The negative impact of BDD on academic life of students is evident by the fact that around $22.2 \%$ of adolescents suffering from BDD reported dropping out of school, either temporarily or permanently (29). This could be attributed to the exhaustion caused by excessive preoccupation with their non-existent defect, leading them to have a reduced and poor quality of sleep. Thus $\mathrm{BDD}$ has negative consequences on the overall health and quality of students lives $(30,31)$

Table 1: Diagnostic criteria of body dysmorphic disorder according to DSM-5 (13).

Diagnostic Criteria of BDD According to DSM-5

\begin{tabular}{|c|c|}
\hline Appearance preoccupations & $\begin{array}{l}\text { The individual must be preoccupied with a defect or flaw in his/her physical appearance that either does not exist or, } \\
\text { if present, is not a matter of concern to others, and the affected individual at least spends an hour a day thinking about } \\
\text { the perceived defect. }\end{array}$ \\
\hline Repetitive behaviors & $\begin{array}{l}\text { There should be a history of the individual performing repetitive, compulsive behaviors about the concerned defect, } \\
\text { such as excessively checking out oneself in the mirror, asking others about the perceived defect, pinching or touching } \\
\text { the concerned flaw, or comparing oneself with others. }\end{array}$ \\
\hline Clinical significance & $\begin{array}{l}\text { The perceived flaw must have unhealthy severe ramifications on the health of the individual and cause severe distress } \\
\text { on the personal, social, and occupational life of the individual. }\end{array}$ \\
\hline $\begin{array}{l}\text { Differentiation from an eating } \\
\text { disorder }\end{array}$ & $\begin{array}{l}\text { If the preoccupations are related to the bodyweight of the individual such that the main focus of concern is being too } \\
\text { fat or too thin, any other eating disorder should be ruled out. If the criteria of any eating disorders are met, the correct } \\
\text { diagnosis should be made. }\end{array}$ \\
\hline \multirow[t]{6}{*}{ Specifiers } & $\begin{array}{l}\text { Once the diagnosis of BDD has been made, the following two specifiers should be considered to identify the subgroups } \\
\text { of BDD: }\end{array}$ \\
\hline & 1) Muscle dysmorphia: \\
\hline & $\begin{array}{l}\text { This variant of BDD is diagnosed if the individual displays concerns of being too lean or not muscular enough and } \\
\text { develops an obsession with bodybuilding and weightlifting to improve his build. Such individuals have been reported } \\
\text { to be more suicidal and prone to substance abuse than those with other forms of BDD. }\end{array}$ \\
\hline & 2) Individual specifier: \\
\hline & This specifier stipulates the degree of insight an individual has and is classified into three categories: \\
\hline & $\begin{array}{l}\text { - With fair insight: The individual acknowledges that the body dysmorphic beliefs are not true or may or may not } \\
\text { be true. } \\
\text { - With poor insight: The individual considers the dysmorphic beliefs to be true. } \\
\text { - No insight present/ delusions: The individual has a firm conviction about the presence of the dysmorphic belief. }\end{array}$ \\
\hline
\end{tabular}

BDD: Body Dysmorphic Disorder 
Table 2: A review of some studies from different countries on body dysmorphic disorder (18-28).

\begin{tabular}{|c|c|c|c|c|c|c|c|c|c|c|c|}
\hline \multirow[b]{2}{*}{ Study } & \multirow[b]{2}{*}{ Location } & \multirow[b]{2}{*}{ Study population } & \multicolumn{3}{|c|}{ Number of participants } & \multirow[b]{2}{*}{$\begin{array}{l}\text { Mean age } \\
\text { (years) }\end{array}$} & \multirow[b]{2}{*}{$\begin{array}{l}\text { Screening } \\
\text { tool }\end{array}$} & \multicolumn{3}{|c|}{$B D D$ prevalence } & \multirow[b]{2}{*}{ Comments } \\
\hline & & & Total & Male & Female & & & $\begin{array}{c}\text { Total } \\
(\%)\end{array}$ & $\begin{array}{c}\text { Male } \\
(\%)\end{array}$ & $\begin{array}{l}\text { Female } \\
\text { (\%) }\end{array}$ & \\
\hline $\begin{array}{l}\text { Cansever A } \\
\text { et al. }(18)\end{array}$ & Turkey & $\begin{array}{l}\text { Female nursing } \\
\text { students }\end{array}$ & 420 & 0 & 420 & 19.1 & $\begin{array}{l}\text { DSM IV } \\
\text { BDDE }\end{array}$ & 4.8 & 0 & 4.8 & $\begin{array}{l}\text { Diagnosis of BDD was made on an } \\
\text { interview using BDDE. }\end{array}$ \\
\hline $\begin{array}{l}\text { Koran } M L \\
\text { et al (19) }\end{array}$ & USA & Adult population & 2048 & 739 & 1309 & $\begin{array}{c}\text { Most partici- } \\
\text { pants were } \geq 55 \\
\text { years }\end{array}$ & $\begin{array}{l}\text { DSM IV } \\
\text { BDD phone } \\
\text { interview }\end{array}$ & 2.4 & 0.8 & 1.6 & $\begin{array}{l}\text { Men were most worried about 'hair' } \\
\text { and women about 'stomach.' }\end{array}$ \\
\hline $\begin{array}{l}\text { Liao Yet } \\
\text { al. }(20)\end{array}$ & China & $\begin{array}{l}\text { First year medical } \\
\text { students }\end{array}$ & 487 & 181 & 306 & 18.5 & $\begin{array}{c}\text { DSM IV } \\
\text { criteria } \\
\text { BDDQ, } \\
\text { DCQ }\end{array}$ & 6 & 0 & 6 & $\begin{array}{l}\text { Other additional scales used in the } \\
\text { study are BSQ, SMAQ, SIAS, and } \\
\text { SDS. }\end{array}$ \\
\hline $\begin{array}{l}\text { Conrado } \\
\text { LA et al. } \\
\quad(21)\end{array}$ & Brazil & $\begin{array}{l}\text { Dermatologic } \\
\text { patients }(300) \text { and } \\
\text { controls }(50)\end{array}$ & 350 & 71 & 279 & 42.2 & BDDQ-DV & 9.1 & N/A & N/A & $\begin{array}{l}\text { BDD was more common among } \\
\text { individuals seeking dermatologic } \\
\text { treatment }(n=31) \text { as compared to the } \\
\text { control group }(n=1) .\end{array}$ \\
\hline $\begin{array}{l}\text { Barah- } \\
\text { mand } U \text { et } \\
\text { al. }(22)\end{array}$ & Iran & $\begin{array}{l}\text { Students from } \\
\text { final year of high } \\
\text { school to first two } \\
\text { years of university }\end{array}$ & 843 & 463 & 380 & 18.1 & MBSRQ-AS & 19.1 & 6.6 & 12.5 & $\begin{array}{l}12.9 \% \text { of the population had comor- } \\
\text { bid social anxiety, while } 6.4 \% \text { had } \\
\text { comorbid obsessive beliefs. Females } \\
\text { reported more social anxiety, while } \\
\text { males reported more obsessive } \\
\text { beliefs. }\end{array}$ \\
\hline $\begin{array}{l}\text { Fatho- } \\
\text { loloom MR } \\
\text { et al. }(23)\end{array}$ & Iran & $\begin{array}{l}\text { Rhinoplasty } \\
\text { patients }\end{array}$ & 130 & 31 & 99 & 26.4 & BDDQ & 31.5 & N/A & N/A & $\begin{array}{l}\text { Among BDD patients, } 29.3 \% \text { had } \\
\text { coexisting depression, and } 26.8 \% \text { had } \\
\text { coexisting anxiety. }\end{array}$ \\
\hline $\begin{array}{l}\text { Brohede } S \\
\text { et al. }(24)\end{array}$ & Sweden & Adult females & 2885 & 0 & 2885 & $\begin{array}{c}\text { Age: } 18-30 \\
(29.2 \%) ; 3-45 \\
(36.4 \%) ; 46-60 \\
(34.4 \%)^{*}\end{array}$ & $\begin{array}{l}\text { DSM IV } \\
\text { BDDQ }\end{array}$ & 2.1 & 0 & 2.1 & $\begin{array}{c}\text { Depression and anxiety were mea- } \\
\text { sured using HADS. The age group } \\
\text { of 18-30 years had higher BDD } \\
\text { prevalence. }\end{array}$ \\
\hline $\begin{array}{l}\text { Schneider } \\
\text { SC et al. } \\
\quad(25)\end{array}$ & Australia & Adolescents & 3149 & 2000 & 1149 & 14.6 & $\begin{array}{l}\text { DSM IV } \\
\text { BDDQ-A }\end{array}$ & 1.7 & N/A & N/A & $\begin{array}{l}\text { The three most commonly disliked } \\
\text { body parts are skin, nose, and hair, } \\
\text { respectively. }\end{array}$ \\
\hline $\begin{array}{l}\text { Ahamed SS } \\
\text { et al. (26) }\end{array}$ & $\begin{array}{l}\text { Saudi } \\
\text { Arabia }\end{array}$ & $\begin{array}{l}\text { Female medical } \\
\text { students }\end{array}$ & 365 & 0 & 365 & 20.0 & BIDQ & 4.4 & 0 & 4.4 & $\begin{array}{l}\text { SIAS scale was used. No significant } \\
\text { association between BDD and social } \\
\text { anxiety was found. Participants were } \\
\text { most concerned about their skin. }\end{array}$ \\
\hline $\begin{array}{l}\text { Buhlmann } \\
\text { Uet al. }(27)\end{array}$ & Germany & $\begin{array}{l}\text { General popula- } \\
\text { tion (18-93 years) }\end{array}$ & 2510 & 1142 & 1368 & 46.9 & $\begin{array}{l}\text { DSM IV } \\
\text { BDD }\end{array}$ & 1.8 & 7 & 1.1 & $\begin{array}{l}\text { BDD affected individuals had a high- } \\
\text { er frequency of suicide ideation and } \\
\text { suicide attempts compared to non- } \\
\text { BDD individuals. History of cosmetic } \\
\text { surgery was more often reported by } \\
\text { body dysmorphic individuals }\end{array}$ \\
\hline $\begin{array}{l}\text { Jangda } A A \\
\text { et al. }(28)\end{array}$ & Pakistan & $\begin{array}{l}\text { University } \\
\text { students }\end{array}$ & 280 & 0 & 280 & 22.5 & $\begin{array}{l}\text { DSM-5 } \\
\text { BIDQ }\end{array}$ & 8.1 & 0 & 8.1 & $\begin{array}{l}\text { BDD was prevalent among female } \\
\text { university students, and weight was } \\
\text { the major focus of concern. }\end{array}$ \\
\hline
\end{tabular}

N/A: Not Available, BDD: Body Dysmorphic Disorder, BDDE: Body Dysmorphic Disorder Examination, BDDQ: Body Dysmorphic Disorder Questionnaire, BDDQ-A: Body Dysmorphic Disorder Questionnaire- Adolescent Version, BDDQ-DV: Body Dysmorphic Disorder Questionnaire Dermatology Version BIDQ: Body Image Disturbance Questionnaire, BSQ: Body Shape Questionnaire, DCQ: Dysmorphic Concern Questionnaire, DSM-IV: Diagnostic and Statistical Manual of Mental Disorders Fourth Edition, DSM-5: Diagnostic and Statistical Manual of Mental Disorders Fifth Edition HADS: Hospital Anxiety and Depression Scale, MBSRQ-AS: Multidimensional Body-Self Relations Questionnaire Appearance Scales, SDS: Self-Rating Depression Scale, SIAS: Social Interaction Anxiety Scale, SMAQ: Swansea Muscularity Attitudes Questionnaire ${ }^{*}$ Mean age was not available and study data has been reported.

\section{Body dysmorphic disorder and weight concerns}

Young individuals believe that they are over or underweight, which leads to body dysmorphia and excessive dietary habits or participation in exhaustive exercises (32). Muscle dysmorphia is a variant of BDD, which is characterized by the development of obsessive thoughts related to one's build. The affected individual aims to exercise and develop more muscle and may even use anabolic steroids. This obsessive habit of bodybuilding may lead to functional impairment later in life (33).

Adolescents who have higher body-mass index are excessively concerned about their body image and have low self-esteem as well as identity issues. Years of struggling with obesity, stigmatization, and peer pressure may lead to an increased negative perception, and eventually having bariatric surgery (34).

\section{Substance abuse in individuals with body dysmorphic disorder}

History of different forms of abuse has been reported by individuals of various ages suffering from BDD. A study by Didie et al. (35) showed that a large number of BDD patients (78.8\%) went through some form of child neglect, emotional neglect, or abuse either emotional, physical, or sexual. Thus a link between the development of BDD and history of abuse was noted. Individuals with a history of abuse and BDD are likely to suffer from mood disor- 


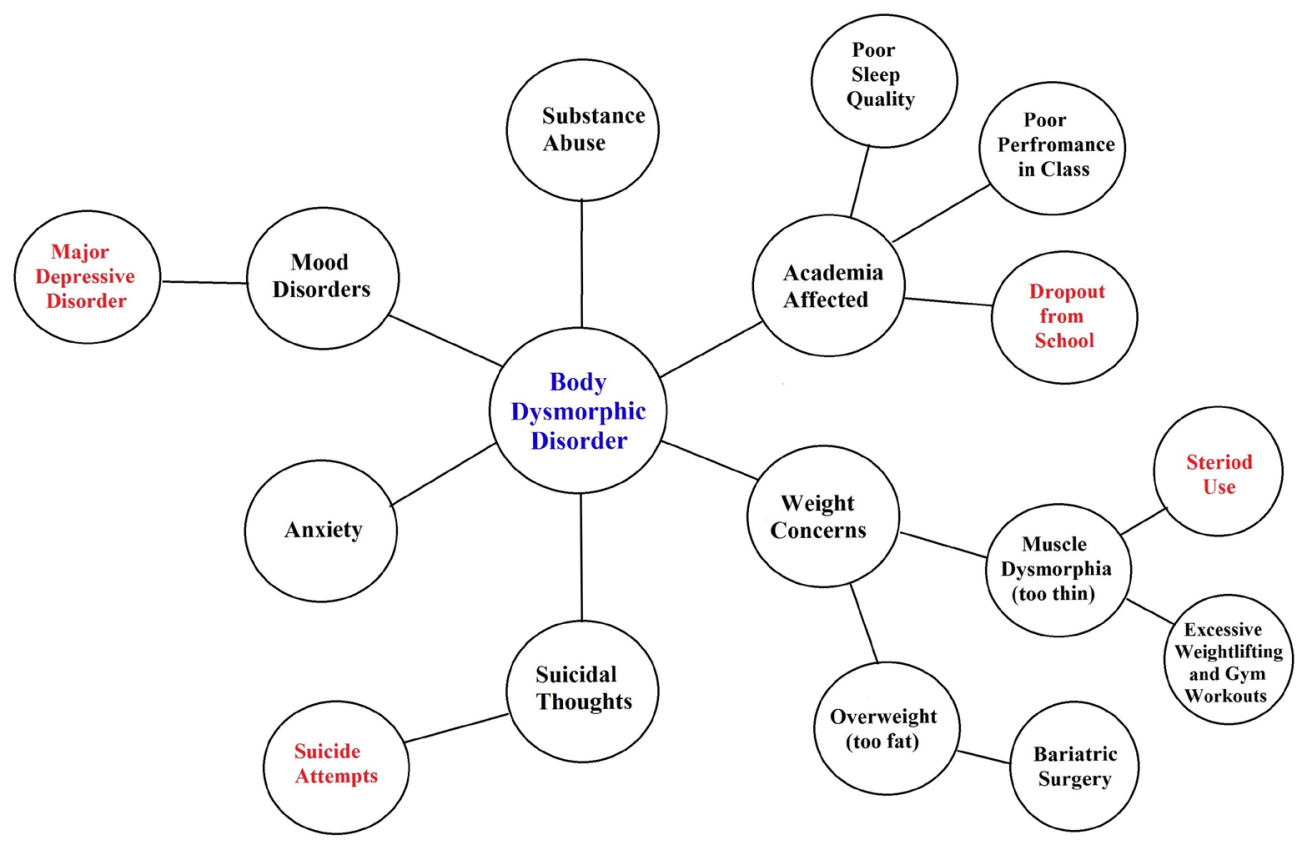

Figure 1: Impacts of body dysmorphic disorder on different aspects of life.

ders, substance abuse, and suicidal thoughts in their adult life (35). Grant et al. (36) reported that $48.9 \%$ of BDD patients had a lifelong history of substance use disorder and $35.8 \%$ developed a lifetime substance dependence, mostly alcohol dependence (29\%). Another crucial fact was that $68 \%$ of the people have remarked that BDD had contributed to their habit of substance abuse. It was also seen that individuals with BDD and a coexisting substance use disorder showed a higher rate of suicide attempts compared to those with just BDD (38.4\% vs. $18.9 \%)$ (36).

\section{Major depressive disorder and body dysmorphic disorder}

Body dysmorphic disorder and OCD have been grouped as Obsessive-Compulsive Related Disorders in the DSM-5. A study investigating the relation of these disorders to anxiety and shame showed that anxiety is an important risk factor for the development of both of these disorders (37). MDD is common in people with $\mathrm{BDD}$, and thus a progressively worsening BDD may hint at a presence of coexisting MDD (38). Individuals with BDD demonstrate an excessive preoccupation with their perceived defect to a degree that affects their mental health. This leads them to be depressed and can often contribute to the development of suicidal predilections $(37,39,40)$. A disturbing aspect of this disorder was demonstrated in a review by Phillips et al. (41) showing that $80 \%$ of the affected individuals had suicidal thoughts, and $24-28 \%$ even attempted suicide.

\section{MANAGEMENT OF BODY DYSMORPHIC DISORDER}

The need for a recognition and management of BDD is urged upon due to several reasons. According to a research by Beilharz et al. (42), the suicidal tendency of a person suffering from this disorder was found to be about 45 times more than the average individual. BDD has been also linked with mood swings, anxiety, depression, and various mental disorders (42). Research conducted by Grant et al. (36) associated BDD with substance abuse, where almost half of the patients developed a lifetime habit of drug abuse.
These alarming consequences of an untreated BDD stress the importance of its timely diagnosis and proper treatment.

Treatment options for BDD include both psychotherapeutic and pharmacological interventions. Recent studies have deemed cognitive-behavioral therapy (CBT), selective serotonin reuptake inhibitors (SSRIs), or a combination of the two as the treatment for BDD (12). CBT is a type of psychosocial talk therapy that identifies maladaptive thoughts and emotional responses and substitutes them with desirable patterns of thinking and behavior. The objective of CBT is first to recognize the problem, then challenge and reverse the harmful thoughts or habits and finally result in an improved quality of life. The goal is also to familiarize the patient with coping mechanisms and prevent future relapses. A standard CBT consists of 12-22 weekly sessions and 3 to 6 months of follow-up sessions. Ample data is available, concluding CBT is the most successful and accepted management option when treating $\operatorname{BDD}(43,44)$.

Selective serotonin reuptake inhibitors, typically used as antidepressants, are used in the treatment of several psychiatric disorders such as depressive and anxiety disorders, social phobias, eating disorders, and panic disorders as well. More commonly used drugs of the class are fluoxetine, paroxetine, escitalopram, among others. These drugs work by limiting the reabsorption of serotonin, thus increasing its extracellular levels. Numerous studies have highlighted the importance and success of SSRIs in the improvement of symptoms and the treatment of $\operatorname{BDD}(43,45)$.

However, along with the efficacy of the treatment, it is crucial to keep an eye on the adverse effects of long-term antidepressant therapy. More common side effects include nausea, vomiting, insomnia, agitation, weight gain, and sexual problems. In contrast, several serious adverse effects can also occur. These adverse effects can be listed as hostility towards others, suicidal tendencies, psychosis, and seizures (43). These side effects often cause significant challenges with treatment adherence. Since BDD is a chronic disorder and demands long-term therapy, continuous monitoring is crucial to avoid the earlier-mentioned side effects of SSRIs. The management of BDD is summarized in Figure 2. 


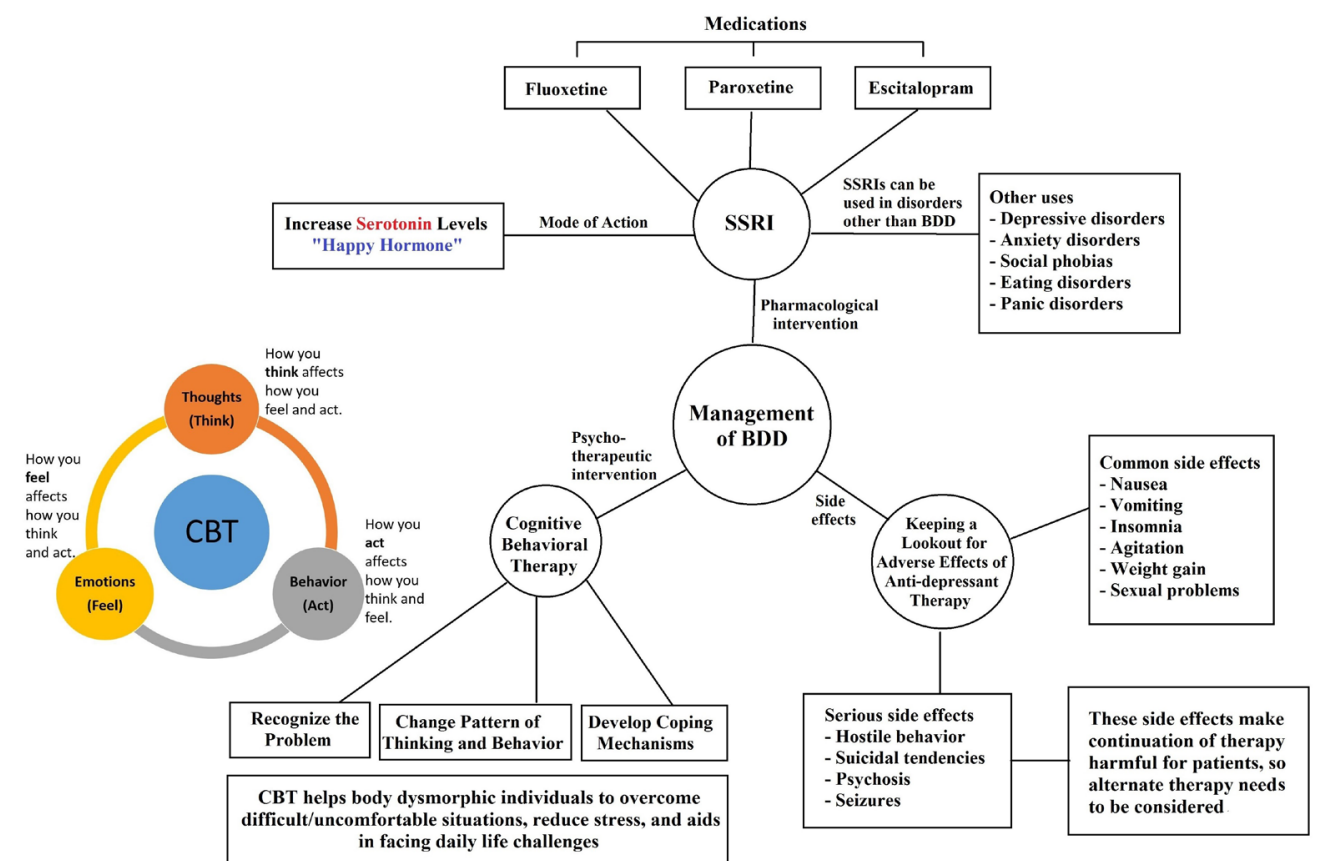

Figure 2: Management of body dysmorphic disorder.

BDD: Body Dysmorphic Disorder, CBT: Cognitive Behavioral Therapy, SSRI: Selective Serotonin Reuptake Inhibitors

\section{FUTURE PROSPECTS AND SUGGESTIONS}

The fact that BDD is not only prevalent but also a seriously damaging condition makes it essential to develop a thorough understanding of the disease. Since most people share just the best parts of their life via social media, it is tough to avoid making comparisons.

On our path to understanding BDD, our first step should be destigmatizing and creating awareness among the general population as well as the health care professionals. Countrywide awareness campaigns and more research should be held on this disorder. Encouraging body positivity and conducting sessions with various psychotherapists may be beneficial for the patients. Avoiding misdiagnosis could accelerate the treatment progress. Many patients are often misdiagnosed with MDD or OCD and that results in wrong treatment strategies (9). After the prompt diagnosis, the treatment should be planned according to the patients' needs; pharmacological treatment and/or cognitive behavioral therapy. Encouraging students with symptoms of BDD to schedule appointments with mental health professionals may avoid serious consequences as well.

The development of self-confidence concerned with one's appearance is a great contributor to an individual's personal and professional growth. Thus, the development of a negative self-image not only harms a person in his/her current life but also hinders his/ her future growth. Still, further studies are needed to prove if this disease becomes an obstacle in the path of academic success.

\section{CONCLUSION}

In conclusion, BDD is a complicated disorder that harms an individual's life in many ways. It can lead to very low self-esteem, extreme anxiety, depression, and suicidal ideation in an individual. It can affect students emotionally as well as academically and can even lead to dropouts from school. It is crucial to identify this dis- order and educate people about body-positivity. Correct diagnosis and adequate management can help the affected individual to have a healthy life again.

\section{Ethics Committee Approval: N/A}

Informed Consent: N/A

Conflict of Interest: The authors declared no conflict of interest.

Author contributions: Concept: FM, JA, SN, AA, ARK. Design: FM, JA, SN, AA, ARK. Supervision: FM, JA, SN, AA, ARK. Resources: FM, JA, SN, AA, ARK. Materials: FM, JA, SN, AA, ARK. Data collection and/or processing FM, JA, SN, AA, ARK. Analysis and/or Interpretation: FM, JA, SN, AA, ARK Literature Search: FM, JA, SN, AA, ARK. Writing Manuscript: FM, JA, SN, AA, ARK. Critical Review: FM, JA, SN, AA, ARK.

Financial disclosure: The authors declared that this study received no financial support.

\section{REFERENCES}

1. Sarwer DB, Spitzer JC. Body image dysmorphic disorder in persons who undergo aesthetic medical treatments. Aesthet Surg J 2012;32(8):999-1009.

2. American Psychiatric Association. Diagnostic and statistical manual of mental disorders. 5th ed. Arlington, VA: 2013.

3. American Psychiatric Association. Obsessive-compulsive and related disorders. In: Diagnostic and statistical manual of mental disorders 5th ed. Arlington, VA: 2013.

4. Philips KA. Diagnosing BDD. Int OCD Found, 2020. (cited June 12, 2020) Available from: URL: https://bdd.iocdf.org/professionals/diagnosis/.

5. Enander J, Ivanov VZ, Mataix-Cols D et al. Prevalence and heritability of body dysmorphic symptoms in adolescents and young adults: a population-based nationwide twin study. Psychol Med 2018;48(16):2740-7.

6. Taqui AM, Shaikh M, Gowani SA et al. Body dysmorphic disorder: gender differences and prevalence in a Pakistani medical student population. BMC Psychiatry 2008;8(1).

7. Suhail M, Salman S, Salman F. Prevalence of body dysmorphic disorder in medical versus nonmedical students: a questionnaire based pilot study. Journal of $\mathrm{Pa}$ kistan Association of Dermatology 2015;25(3):162-8.

8. Perkins A. Body dysmorphic disorder: the drive for perfection. Nursing 2019;49(3):28-33

9. Phillips KA. The broken mirror: Understanding and treating body dysmorphic disorder: Oxford University Press. USA; 2005.

10. Phillips KA, Nierenberg AA, Brendel G et al. Prevalence and clinical features of body dysmorphic disorder in atypical major depression. J Nerv Ment Dis 1996;184(2):125-9. 
11. Zimmerman M, Mattia JI. Body dysmorphic disorder in psychiatric outpatients: recognition, prevalence, comorbidity, demographic, and clinical correlates. Compr Psychiatry 1998;39(5):265-70.

12. Hong K, Nezgovorova V, Hollander E. New perspectives in the treatment of body dysmorphic disorder. F1000Res 2018;23(7):361

13. Substance Abuse and Mental Health Services Administration. DSM-5 Changes: Implications for Child Serious Emotional Disturbance. Rockville (MD): Substance Abuse and Mental Health Services Administration (US); 2016.

14. International OCD Foundation. Assessment tools for BDD. (cited June 12, 2020) Available from: URL: https://bdd.iocdf.org/professionals/assessment-tools-forbdd/.

15. Thomas F. Cash. Body Image Assessments: BIDQ. (cited June 12, 2020) Available from: URL: http://www.body-images.com/assessments/bidq.html.

16. Phillips KA. Body dysmorphic disorder: Advances in research and clinical practice: Oxford University Press; 2017.

17. Veale D, Gledhill LJ, Christodoulou P et al. Body dysmorphic disorder in different settings: A systematic review and estimated weighted prevalence. Body Image 2016;18:168-86.

18. Cansever A, Uzun Ö, Dönmez E et al. The prevalence and clinical features of body dysmorphic disorder in college students: a study in a Turkish sample. Compr Psychiatry 2003;44(1):60-4

19. Koran LM, Abujaoude E, Large MD et al. The prevalence of body dysmorphic disorder in the United States adult population. CNS Spectr 2008;13(4):316-22.

20. Liao Y, Knoesen NP, Deng Y et al. Body dysmorphic disorder, social anxiety and depressive symptoms in Chinese medical students. Soc Psychiatry Psychiatr Epidemiol 2010;45(10):963-71.

21. Conrado LA, Hounie AG, Diniz JB et al. Body dysmorphic disorder among dermatologic patients: Prevalence and clinical features. J Am Acad Dermatol 2010;63(2):235-43.

22. Barahmand U, Shahbazi Z. Prevalence of and associations between body dysmorphic concerns, obsessive beliefs and social anxiety. Asia Pac Psychiatry 2015;7(1):54-63.

23. Fathololoomi MR, Tabrizi AG, Bafghi AF et al. Body dysmorphic disorder in aesthetic rhinoplasty candidates. Pak J Med Sci 2013;29(1):197-200.

24. Brohede S, Wingren G, Wijma B et al. Prevalence of body dysmorphic disorder among Swedish women: a population-based study. Compr Psychiatry 2015;58:108-15.

25. Schneider SC, Turner CM, Mond J et al. Prevalence and correlates of body dysmorphic disorder in a community sample of adolescents. Aust N Z J Psychiatry 2017;51(6):595-603

26. Ahamed SS, Enani J, Alfaraidi L et al. Prevalence of body dysmorphic disorder and its association with body features in female medical students. Iran J Psychiatry Behav Sci 2016;10(2)

27. Buhlmann U, Glaesmer H, Mewes R et al. Updates on the prevalence of body dysmorphic disorder: a population-based survey. Psychiatry Res 2010;178(1):171-5.
28. Jangda AA, Uddin MF, Jangda MA et al. Body dysmorphic disorder: a serious concern for our young generation. Asian J Psychiatr 2017;28:3.

29. Phillips KA, Didie ER, Menard W et al. Clinical features of body dysmorphic disorder in adolescents and adults. Psychiatry Res 2006;141(3):305-14

30. Didie ER, Tortolani C, Walters $\mathrm{M}$ et al. Social functioning in body dysmorphic disorder: assessment considerations. Psychiatr Q 2006;77(3):223-9.

31. Phillips KA, Menard W, Fay $\mathrm{C}$ et al. Psychosocial functioning and quality of life in body dysmorphic disorder. Compr Psychiatry 2005;46(4):254-60.

32. Dingemans AE, van Rood YR, de Groot I et al. Body dysmorphic disorder in patients with an eating disorder: Prevalence and characteristics. Int J Eat Disorder 2012;45(4):562-9.

33. Nieuwoudt JE, Zhou S, Coutts RA et al. Muscle dysmorphia: Current research and potential classification as a disorder. Psychol Sport and Exerc 2012;13(5):569-77.

34. Gilmartin J. Body image concerns amongst massive weight loss patients. J Clin Nurs 2013;22(9-10):1299-309.

35. Didie ER, Tortolani CC, Pope CG et al. Childhood abuse and neglect in body dysmorphic disorder. Child Abuse Negl 2006;30(10):1105-15.

36. Grant JE, Menard W, Pagano ME et al. Substance use disorders in individuals with body dysmorphic disorder. J Clin Psychiatry 2005;66(3):309-16.

37. Weingarden $\mathrm{H}$, Renshaw $\mathrm{KD}$, Wilhelm $\mathrm{S}$ et al. Anxiety and shame as risk factors for depression, suicidality, and functional impairment in body dysmorphic disorder and obsessive compulsive disorder. J Nerv Ment Dis 2016;204(11):832-9.

38. Phillips KA, Didie ER, Menard W. Clinical features and correlates of major depressive disorder in individuals with body dysmorphic disorder. J Affect Disord 2007;97(1-3):129-35.

39. Fang A, Hofmann SG. Relationship between social anxiety disorder and body dysmorphic disorder. Clin Psychol Rev 2010;30(8):1040-8.

40. Angelakis I, Gooding PA, Panagioti M. Suicidality in body dysmorphic disorder (BDD): A systematic review with meta-analysis. Clin Psychol Rev 2016;49:55-66.

41. Phillips KA, Coles ME, Menard W et al. Suicidal ideation and suicide attempts in body dysmorphic disorder. J Clin Psychiatry 2005;66(6):717-25.

42. Beilharz F, Castle DJ, Phillipou A et al. Visual training program for body dysmorphic disorder: protocol for a novel intervention pilot and feasibility trial. Pilot Feasibility Stud 2018;4:189.

43. Singh AR, Veale D. Understanding and treating body dysmorphic disorder. Indian J Psychiatry 2019;61(7):131-5.

44. Harrison A, Fernández de la Cruz L, Enander J et al. Cognitive-behavioral therapy for body dysmorphic disorder: A systematic review and meta-analysis of randomized controlled trials. Clin Psychol Rev 2016;48:43-51.

45. Phillipou A, Rossell SL, Wilding HE et al. Randomised controlled trials of psychological \& pharmacological treatments for body dysmorphic disorder: A systematic review. Psychiatry Res 2016;245:179-85. 